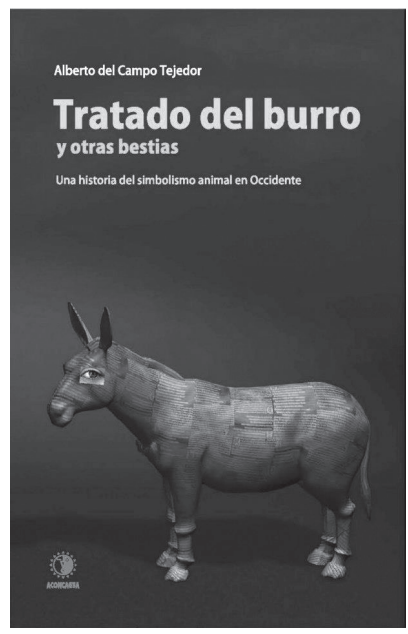

\title{
ALBERTO DEL CAMPO TEJEDOR \\ Tratado del burro y otras bestias. \\ Una historia del simbolismo animal \\ en Occidente.
}

AÑO: 2012

ISBN: 978-84-96178-88-5

PÁGINAS: 586

SEVILLA: Aconcagua Libros

SANTIAGO MONTERO-CRUZADA / UNIVERSIDAD PABLO DE OLAVIDE

\section{Reseña}

Con la máxima de Persio como jáquima, Auriculas asini quis non habet?, se apuntan los aspectos principales que han llevado a realizar una revisión analítica y crítica del contenido de la obra Tratado del burro y otras bestias. Una historia del simbolismo animal en Occidente, del antropólogo Alberto del Campo Tejedor.

Sirva este párrafo como aproximación al tratado para, una vez caracterizado, adentrarse de lleno en las cuestiones y pensamientos originados durante y mediante la lectura del libro. Volumen imprescindible para quien quiera indagar en el mundo de las relaciones humano-animales, es un escrito sobre la construcción social de las realidades a través del simbolismo animal. Partiendo desde una perspectiva interpretativa, quizás innovadora para la filología o la historia desde el punto de vista que plantea el autor, con carácter marcadamente antropológico, la historia cultural de los animales en Occidente y su simbología muestran la ambivalencia de significados que los humanos han otorgado a sus coetáneos animales desde los orígenes de las civilizaciones occidentales hasta la actualidad. En ellas, o a través de ellas, los humanos expresan sus formas de vida, poniendo de manifiesto las cotidianeidades, las vivencias y las creencias, los triunfos y miedos que en las determinadas épocas se han 
ido conformando. Así, la ecléctica de improntas sobre los animales, que el antropólogo desarrolla con un particular y riguroso estilo literariocientífico, permite comprender cómo las relaciones humanas con el entorno han sido dinámicamente cambiantes a lo largo de los tiempos. La comparación etnográfica, junto a la revisión de ensayos, libros, facecias, apotegmas, bestiarios, fábulas, esculturas, pinturas, cuentos, exégesis religiosas o tratados filosóficos, focalizados sobre el asno y su polisemia simbólica, pero extensible al resto de criaturas no humanas, se introducen de lleno en las asociaciones alegóricas culturalmente convenidas para representar la existencia humana a través de lo animal. Por ello se condensan multiplicidad de significados, ambigüedades y paradojas desde diferentes creaciones expresivas que hacen pasar, y pensar, de lo concreto a lo trascendente, de homogeneidades a heterogeneidades. Los animales en general, pero particularmente el burro, toman existencia real más allá de los ámbitos materiales y empíricos donde se hallan como seres, siendo la simbolización el fundamento de esa otra realidad que, al mismo tiempo, es retroproyectiva.

El reconocimiento explícito que se hace del libro no impide que se argumenten críticamente las cuestiones que, a juicio, han llevado su contenido a la reflexión. En ese sentido, el discurso que emplea el autor hace que el lector quede atrapado en el simbolismo animal debido a sus repetidas tramas de significado que a lo largo de la historia se le han proyectado, siendo repetitivos hasta la actualidad. El libro se hace eco de ellas y las reproduce tantas veces que, finalmente, no queda claro si en el Barroco, por ejemplo, el burro representaba la inocencia, la humildad y la sencillez o, por el contrario, era tomado como imagen de la rijosidad, la lujuria y el pecado. Evidentemente, la Historia y las historias dictan el significado al cual se ha aferrado el escritor, pero en falta se echa tener una síntesis de épocas y de vaivenes simbólicos, por ejemplo, a modo de conclusión. A propósito de tal, una conclusión breve no hubiera estado de más, sobre todo teniendo en cuenta esto, una recopilación literaria de todo lo expuesto, aun a riesgo de minimizar todo el trabajo de investigación y simplificarlo a unas cuantas páginas finales. Esto, junto a una clara convicción ético-moral, que esbozada tímidamente en el papel se entremete en muchos apartados finales cuando empiezan a surgir los discursos proteccionistas sobre los animales, sería una forma más adecuada de terminar. Sabemos que la "objetividad» en la «ciencia» es una artificialidad de los «científicos», aspecto muy tenido en cuenta en el libro; por lo tanto, posicionarse política, ética o moralmente quedaría ya lejos de impregnar el texto con prejuicios. 
Del mismo modo, a lo largo del contenido se encuentran escasas alusiones a la cuestión del género, pues todo, o casi todo, hace referencia al burro. Macho, semental o rucio, en pocas ocasiones el simbolismo giró en torno a la hembra. Cierto es que algo se recoge en el libro, pero nunca llega al protagonismo del macho jumento. El sentido de la significación simbólica que se ha construido en Occidente a lo largo de la historia ha sido masculina (y seguro que en más contextos geoculturales), androcéntrica se podría decir, por lo que poco se podrá encontrar, hasta el siglo $\mathrm{XX}$, de simbolizaciones, metáforas o alegorías con respecto a la hembra, a la burra. Por otro lado, y conectando con lo anterior, la mayoría de obras recogidas son de autores hombres. Quizás porque solo eran ellos los que escribían — con lo cual se apoya lo anterior-, o quizás porque únicamente eran los que se relacionaban con el asno, convencido se está que las mujeres han mantenido relaciones con estas bestias y, por descontado, también hubiera gustado que se hubiesen recogido. Que pueda haber textos donde se exprese explícitamente la relación de las mujeres con los animales y se hayan apartado, que se hayan omitido o no, quedan como interrogantes. Aun así habría sido bueno encontrar una reflexión de estas características al principio del libro, pues eso habría hecho opaca esta reflexión que, por lo general y desgraciadamente, no se visibilizan a menos que se tengan muy presentes aunque, indudablemente, se sepan.

Con respecto al orden cronológico tratado, siendo perfecto en su estructura, se produce no pocas veces una dispersión histórica, yendo de detrás hacia delante, de delante hacia el medio, y así repetidamente. Se pierde la lectura en la historia debido a las extensas explicaciones del origen y las bases de los textos en los que se basa el antropólogo para conformar el relato, estudiando al detalle, a veces, contextos innecesarios para el sentido del libro, haciendo tropezar el flujo discursivo.

Para concluir esta reseña se objetan dos cuestiones más. La primera tiene que ver con la parada repentina que se realiza sobre la temática en el Barroco, momento en el que se minimizan las alusiones a los bestiarios y a los animales de forma general para centrarse la narración solamente en el jumento. Esto desproporciona el resto de los inicios de los capítulos ya tratados con anterioridad. Evidentemente, el libro versa sobre el burro, pero en el subtítulo también se menciona a otras bestias, que hasta el período indicado sí quedan recogidas, pero de ahí hasta el final poco o nada se habla del simbolismo animal de otras especies. Quizás no sea esto una crítica sino más bien algo que hubiera agradado encontrarse hasta el final como se hizo desde el principio hasta los siglos XVI y XVII.

La segunda sí que tiene el sentido preciso de crítica analítica. Aunque a lo largo del libro se va mencionando el carácter relacional entre las vidas 
de humanos y animales, no pudiéndose entender la realidad sin prestar atención a los compañeros de vida (ya sea la del humano o la del animal), existe en el discurso cierta profusión a separar la naturaleza y la cultura. No queda claro cómo esta dicotomía, creada en Occidente y que perdura hoy más que nunca, se fundamenta desde aparatos ideológicos que en cada período histórico son cambiantes y que desvelan una realidad que no se corresponde, la mayoría de las veces, con la realidad misma. Las relaciones entre humanos y animales forman parte de un mundo singularizado por las representaciones homogéneas que los humanos proyectan al explicar su existencia con/para los animales. También en las relaciones prácticas, en los gestos, sentimientos, actitudes o comportamientos, queda reflejada esta unión, como bien se apunta en el libro, siendo los animales más que elementos utilitarios compañeros de vivencias en planos morales y simbólicos. Las relaciones humano-animales, como están expuestas en el tratado, rompen, efectivamente, la dicotomía naturalezacultura, aspecto muy potente para desarticular discursos proteccionistas como los que se exponen al final del relato. Sin embargo, la inexactitud terminológica o la no argumentación explícita dan oportunidad de error, es decir, se asemeja a la distinción y separa lo fuertemente relacional, forzando una realidad dicotómica. Se habla a lo largo del relato, por ejemplo, de «conexión con la naturaleza» o de «naturaleza», apareciendo así una categoría conceptual aislada a la cual los humanos se acercan o se alejan, presentándose en dos esferas diferentes.

La atención que presta el autor a los rituales contemporáneos del ciclo anual alude a esto que se está comentando, pero sin afrontarlo definitivamente desde una perspectiva monista. No es casualidad que en los diversos rituales religioso-festivos que se describen se aprecien la intensidad relacional humano-animal y, por lo tanto, donde manifiestamente la dicotomía naturaleza-cultura pierde el carácter separador. En ese sentido, haber ahondado desde el principio, y especialmente en esa última parte, en la idea de la falsa antinomia, habría dado al texto un carácter más flexible y exhaustivo en cuanto a la interpretación de la realidad. Este carácter se pierde cuando se propone a la «naturaleza» y al "ser humano" como entes autónomos, por más que en el argumento se evidencie con otros discursos, sin explicitar su mutua construcción.

Los animales y los humanos han pertenecido, también en Occidente, a una misma comunidad, ambos sujetos a las mismas reglas de existencia hasta que distintos modelos teoréticos fueron progresivamente apartándolos para establecer jerarquizaciones que, a su pesar, no se reproducen en circunstancias concretas. Las continuidades entre humanos y animales eran patentes hasta que el concepto de «naturaleza», que en muchas so- 
ciedades no existía, fue impregnando como categoría analítica, de explicación y de poder. Esto se hace explícito en símbolos, rituales y prácticas, siendo otros seres no humanos sujetos sociales en la misma medida en que lo son los humanos, como implícitamente se recoge en el libro. Por ello, utilizar «naturaleza» como concepto explicativo, o no argumentar estas cuestiones onto-epistemológicas, enturbian el posible discurso relacional.

Quizás haya que hablar en la época y contexto actual, y en los lugares donde queden férreas vinculaciones entre humanos y animales, de "momentos unificadores y circunstancias separadoras", pues aquellas categorías creadas de "naturaleza» empapan cada vez más, como aparato ideológico contemporáneo y de poder, las esferas donde este concepto no se hallaba. Y es precisamente en la muerte del animal donde esto se observa. La unión relacional de vida y muerte, del devenir y el porvenir, donde las cosmologías eran producto de la relación con los «iguales» animales hasta mediados del siglo pasado, no puede pasar desapercibida ni siquiera en el lenguaje.

Con estas salvedades, la obra reseñada, como excelente trabajo de su autor, muestra cómo hay que afrontar el compromiso desde las ciencias sociales, y especialmente desde la antropología, para adentrarse en estos ámbitos ignorados y marginales desde una perspectiva profunda, densa e interpretativa en este lugar del mundo que damos a llamar Occidente. 